$\begin{array}{ll}\text { Research Square } & \begin{array}{l}\text { Preprints are preliminary reports that have not undergone peer review. } \\ \text { They should not be considered conclusive, used to inform clinical practice, } \\ \text { or referenced by the media as validated information. }\end{array}\end{array}$

\title{
Are citizen juries and assemblies on climate change driving democratic climate policymaking? An exploration of two case studies in the United Kingdom
}

Rebecca Wells

LSE: The London School of Economics and Political Science

Candice Howarth ( $\sim$ c.howarth@lse.ac.uk)

Grantham Research Institute on Climate Change and the Environment, London School of Economics and Political Science https://orcid.org/0000-00032132-5747

Lina I. Brand-Correa

University of Leeds Faculty of Social Sciences

Research Article

Keywords: Climate policy, democratic deliberative process, citizen jury, citizen assembly

Posted Date: March 29th, 2021

DOI: https://doi.org/10.21203/rs.3.rs-273650/v1

License: (c) (i) This work is licensed under a Creative Commons Attribution 4.0 International License. Read Full License 


\begin{abstract}
In light of increasing pressure to deliver climate action targets, and the growing role of citizens in raising the importance of the issue, deliberative democratic processes (e.g. Citizen Juries and Citizen Assemblies) on climate change are increasingly being used to provide a voice to citizens in climate change decisionmaking. Through a comparative case study of two processes that ran in the UK in 2019 (the Leeds Climate Change Citizens' Jury and the Oxford Citizens' Assembly on Climate Change), this paper investigates how far Citizen Assemblies and Juries on climate change are increasing citizen engagement on climate change and creating more citizen-centred climate policy-making. Interviews were conducted with policy-makers, councillors, professional facilitators and others involved in running these processes to assess motivations for conducting these, their structure and the impact and influence they had. The findings suggest the impact of these processes is not uniform: they have an indirect impact on policymaking by creating momentum around climate action and supporting the introduction of pre-planned or pre-existing policies rather than a direct impact by being truly being citizen-centred policymaking processes or conducive to new climate policy. We conclude with reflections on how these processes give elected representatives a public mandate on climate change, that they help to identify more nuanced and in-depth public opinions in a fair and informed way, yet it can be challenging to embed citizen juries and assemblies in wider democratic processes.
\end{abstract}

\title{
1. Introduction
}

Current UK climate policies are not sufficient to meet UK climate targets (Committee on Climate Change, 2019). Yet, in the past few years the issue of climate change has increasingly become a key concern for citizens in the UK as a result of the momentum built up after the 2018 report on $\mathrm{Global}$ Warming of $1.5^{\circ} \mathrm{C}$ by the Intergovernmental Panel on Climate Change (IPCC) and subsequent movements such as the Climate School Strikes and Extinction Rebellion (XR) (Rode, 2019). A global survey of public attitudes conducted in 2020 by UNDP showed that over $64 \%$ of people worldwide recognise that climate change is a global emergency (UNDP, 2020), and a UK survey conducted in October 2019 found that when asked what the UK's most important issue to tackle in the next 20 years is, climate change had become one of the two most frequently mentioned responses in comparison to being 13th three years before. Additionally, the survey found that the UK government was assigned the main responsibility to prepare the country for climate change and mitigate it (Steentjes et al., 2020). This suggests that citizens are becoming increasingly concerned about climate change and that there is desire for the government to take the lead on tackling it, building up pressure for politicians and policy-makers to adopt more stringent climate policies (Steentjes, et al., 2020 ).

Citizen Juries and Assemblies on climate change are increasingly being run at every level of governance in the UK, from the first conducted in Camden (July 2019) to the national level UK Climate Assembly (January-May 2020). They were promoted since the wave of climate emergency declarations beginning with Bristol in 2018, and to date (February 2021) there have been twenty climate-related mini-publics in the UK and a range of other forms of participatory engagement on climate change (Howarth et al., 2021). It has been argued that these deliberative tools are a method of increasing citizen engagement, bridging the gap and building trust between the scientific, political and social consensus on climate change and increasing the democratic legitimacy of climate policies by creating more citizen-centred policy-making (Willis, 2020; Kythreotis \& et al., 2019; Howarth, et al., 2020; Smith \& Wales, 2000; Willis, 2018; Devaney, et al., 2020; Capstick, et al., 2020). However, as Citizen Juries and Assemblies on climate change only emerged in the UK in 2019, little research has been conducted into the extent to which these processes actually have an impact and promote broader citizen engagement on climate change policy-making. Thus, through a comparative case study of the Oxford Citizens' Assembly on Climate Change and the Leeds Climate Change Citizens Jury this paper will investigate how these processes may differ in practice, the impact they are having on policy and how they are engaging the public into climate change debates.

\section{Literature Review}

\subsection{The case for more public participation on climate change policymaking}

Many scholars have argued that increased public participation in climate policy formulation is required in order to help bridge the gap between the scientific and social consensus on climate change, increase authorities' awareness of the wider public mandate for action on climate change and increasing the legitimacy of climate policies (Willis, 2020; Kythreotis \& et al., 2019; Howarth, et al., 2020). While politicians are aware of what protestors and activists think, they lack a clear sense of the wider public mandate for climate action and face constraints such as lobbying by powerful corporations and five-year electoral cycles, preventing them from proposing the bold changes required to address climate change (Extinction Rebellion Citizens' Assemblies Working Group, 2019; Willis, 2019). Additionally, although climate change is a complex issue laden with scientific and technical detail, policy options for tackling it present complex choices among interests and values, making policy choices political, social, cultural and economic (Dietz \& Stern, 2008). Therefore, decisions should not be taken exclusively by experts, but rather discussed and negotiated in the political arena, with both elected representatives and the public at large (Howarth et al., 2020).

Despite these challenges, until recently few attempts have been made to engage citizens or local areas in the need for, or benefits of, the transition to a zerocarbon society (Willis, 2019). When policies are constructed without public engagement and support, the legitimacy of formal climate policy decisions may be undermined and there is a risk of public resistance. An example of this was the 'gilets jaunes' protests in 2019, which emerged in France after the introduction of a fuel tax which was felt to disproportionately impact low-income households (Chrisafis, 2018). Furthermore, there is evidence that when climate policy design does not take procedural justice into account (including proper participation options for affected communities), their outcomes are indeed unjust and socially negative (Lamb et al., 2020). Thus, many argue that citizens should be involved in shaping climate policy (Dietz \& Stern, 2008; Capstick, et al., 2020; Niemeyer, 2013; Kythreotis \& et al., 2019; Svara \& Denhardt, 2010).

\subsection{Citizens' Assemblies and Juries: tools for including the public in decision-making on climate change}

Page 2/12 
Citizens' Assemblies and Juries are part of a suit of processes with deliberation at its heart. Interest in these has grown as a result of discontent with the confrontational and manipulative elements of current democratic practices and political discourses (Smith \& Wales, 2000). Their proponents argue that deliberative processes improve the legitimacy and the quality of outcomes because, through meaningful deliberation, people engage in providing each other with compelling reasons to support or oppose particular proposals (Lafont, 2017).

Citizen assemblies and juries, commonly called 'mini-publics', work very similarly. They are often commissioned by an actor, usually an institution with decision-making capacity (e.g. a local authority, national government or a regulatory body) and are composed of a randomly selected inclusive group of citizens, small enough to be genuinely deliberative. Citizen assemblies usually include 50-160 people, whereas citizen juries tend to include 12-30 people making them a smaller and therefore cheaper option (Bryant, 2019; Roberts \& Escobar, 2015). An independent oversight panel or advisory board made up of key stakeholders is often set up to oversee the process (Wakeford, et al., 2015). Participants receive expert information on a particular issue, cross-examine experts and deliberate with each other discussing different perspectives and trade-offs and coming up with a series of informed and considered recommendations of how to deal with that issue (Goodin \& Dryzek, 2006; Smith \& Wales, 2000; Roberts \& Escobar, 2015).

Deliberative democracy tools can be used to engage with citizens by creating a structured dialogue between citizens, experts and politicians in order to chart a collaborative way forward on climate change (Howarth et al., 2020; Willis, 2020). Carpini et al. (2004) argue that well-structured deliberation is expected to produce a number of positive democratic outcomes, which can help address issues associated with climate change as a policy issue. These positive outcomes include enhancing faith in the democratic process, creating more informed political decision-making with public evidence and increasing the legitimacy of policies. Therefore, utilising the tools of deliberation may help address several issues stalling stronger climate policy action, as well as making sure climate policies result in more just social outcomes.

The outcomes of these processes are shaped by the motivation for them being commissioned, the stage in the decision-making process at which they are commissioned and how they are designed and delivered in practice (Bryant \& Stone, 2020). Research into how the outputs of deliberative tools feed into traditional political structures and the influence they have on public policy decision-making is limited, and it is difficult to clearly identify the impact that citizen assemblies and juries have, as often the recommendations produced have an advisory role and compete with advice from other groups (Bryant \& Hall, 2017; Flinders et al, 2015; Font \& Smith, 2013). Font and Smith $(2013$, p. 1) claim that generally participatory processes only have a limited impact on final policies. Although there are instances where recommendations made by citizen juries and assemblies are referenced in and reflected in a council's climate policy, it is difficult to prove whether such policies would have been put in place regardless (Bryant \& Stone, 2020). Thus, their impact on climate policy is by no means uniform and further research is needed in order to better ascertain in more detail the specific value they add.

The influence of citizens' juries and assemblies on policy is complex and there are several ways in which a recommendation could be seen as being adopted. For example, through an immediate response by the commissioning body, formal acceptance of the recommendations by the authority, the appearance of a recommendation in policy documents or work programmes, or the actual implementation of the recommendation (Font \& Smith, 2013). The recommendations of mini-publics can also be put for confirmation to the rest of the citizenry through a referendum. In addition, they can create a strong political platform for action by providing elected representatives with a political mandate on climate change which enables them to be more ambitious in their climate action (Bryant \& Stone, 2020). Therefore, this study aims to investigate policy-makers perspectives on how these processes are influencing city-level climate policy in practice.

\subsection{Contribution to broader public engagement on climate change}

Citizen engagement involves collaborating and empowering citizens in decision-making, whereas citizen participation is often used to inform and consult with citizens to gain their views, assistance and support (Svara \& Denhardt, 2010). The level of citizen engagement can be assessed according to whether citizens have an opportunity to discuss ideas or efforts with other citizens and officials, whether engagement activities are citizen-centred, and whether decisionmakers are willing to listen and take the results of the processes into decision-making (Svara \& Denhardt, 2010). Thus, although citizen juries and assemblies meet many of these criteria, the extent to which decision-makers take the results of the process into account varies, and this study will attempt assess the impact these processes are having on decision-making in different contexts.

Citizen assemblies and juries on climate change can help to identify more nuanced and in-depth public opinions reached in a fair and informed way than is achieved by polling or surveys, testing and discussing a range of approaches to climate action and creating space for public engagement within policymaking by producing a set of prioritised recommendations (Bryant \& Stone, 2020). Therefore, they are a structured way of giving citizens the knowledge required on climate change and supporting them to collectively come up with policy recommendations which demonstrate the public mandate for climate action (Howarth et al., 2020). Additionally, they may increase momentum for action as a mandate put forward in a robust citizen assembly or jury process may be more difficult to dismiss than the ideas of left-leaning environmental campaigners (Bryant, 2019).

If well publicised and acted on, citizen assemblies or juries may increase trust in government, a lack of which is a key issue in tackling climate change (Howarth, et al., 2020; Willis, 2020). Yet, many local authorities fail to ignite a wider public conversation around citizen assemblies and juries, and the potential for these processes to be a tool to start or enhance a wider public dialogue on climate change is often neglected (Bryant \& Stone, 2020). Public engagement beyond the formal process of the citizen jury or assembly such as through media coverage of process and follow-up events can contribute to engaging and communicating with the public more deeply on the outcomes of the process and climate change and the transition to low-carbon societies more generally, and can provide a means whereby decision-makers can be held to the recommendations made (Delap, 2001; Devaney et al., 2020; Capstick et al., 2020). For example, in France a large proportion of the population engaged with their national climate assembly through the media, generating a broader national debate. As a result, $70 \%$ of people in France have heard of the Assembly, and $62 \%$ are supportive of the recommendations it produced (Wilson \& Mellier, 2020).

\section{Methodology}


Capstick et al. (2020) claims that there is a need for research to compare and contrast different methods used in the growing number of national and local citizen assembly processes. It is also important to understand how citizen assemblies and juries on climate change are being used, as they may be used as a short-term consultation tool to give public legitimacy to political decisions which have already been made rather than to promote citizen engagement in policymaking and debates. Thus, the way in which climate change is framed in these processes and the topics which are discussed is important because it could influence the conclusions and recommendations reached (Wakeford et al., 2015). Therefore, this study aims to fill this gap by comparing the Oxford Citizen Assembly on Climate Change and the Leeds Climate Change Citizen Jury, both conducted in 2019 in the UK, to assess the extent to which these processes are promoting citizen engagement in practice.

\subsection{Methodological Approach}

This research aimed to investigate the impact that citizen assemblies and juries on climate change are having on citizen engagement and climate policymaking in UK cities. A qualitative research design was adopted in order gain understanding of key actors' perspectives and experiences from their involvement in the processes and climate policy-making in the cities more generally, through rich and detailed data gathered during interviews, going beyond official reports and policy statements (Seale, et al., 2011).

A purposive sampling approach was adopted where those who were involved in running the processes in Oxford and Leeds directly including City Councillors, policy-makers, facilitators and members of the oversight and advisory group, or those who were involved in climate policy-making in the city councils more generally were approached for interviews. These individuals presented information-rich cases in relation to the research aims (Baxter \& Eyles, 1997; Braun \& Clarke, 2018). Thereafter, a snowballing approach was used by asking interviewees for suggestions in order to reach others who were involved but not mentioned in public reports; a total of thirteen individuals were interviewed (Table 1). A semi-structured interview technique was adopted as this allowed the study's aims to be investigated by analysing common patterns and themes in interviews through the use of an interview guide whilst maintaining scope for unanticipated themes to be further explored by asking unplanned questions, allowing for more thorough analysis (Howarth, et al., 2018; Braun \& Clarke, 2018, p. 78).

For the purpose of anonymity and confidentiality, all names and positions of participants were coded. Interviews were audio-recorded with the participants consent and were transcribed by the researcher, and a thematic analysis of transcripts was carried out using NVivo software. The research adopted a grounded approach, where nodes were built up whilst analysing interviews in order to identify common themes. The nodes were then reviewed, refined, and collapsed into primary and secondary nodes to provide more depth of analysis (Fuji, 2018; Rapley, 2011). Once the nodes were finalised, the transcripts were reviewed to ensure coding was consistent.

The following themes were covered in the interviews: (i) reasons why interviewees thought a citizens jury or assembly on climate change was used; (ii) thoughts on the structure of the citizens' jury or assembly; (iii) thoughts on the recommendations produced; and (iv) how influential interviewees thought the process has been in terms of climate policy and citizen engagement in the city.

Table 1

Table of participants, coded

\begin{tabular}{|lll|}
\hline Code & Meaning & Number of interviewees \\
\hline LGO & Local Government, Oxford & $4(\mathrm{LGO1}, \mathrm{LGO2}, \mathrm{LGO3}, \mathrm{LGO4})$ \\
\hline LGL & Local Government, Leeds & $4(\mathrm{LGL1}, \mathrm{LGL2}, \mathrm{LGL3}, \mathrm{LGL} 4)$ \\
\hline $\mathrm{PO}$ & Practitioner for Oxford Citizens' Assembly & $1(\mathrm{PO})$ \\
\hline $\mathrm{PL}$ & Practitioner for Leeds Citizens' Jury & $1(\mathrm{PL})$ \\
\hline $\mathrm{OO}$ & Involved in running the Oxford Assembly & $2(\mathrm{OO1}, \mathrm{OO2})$ \\
\hline $\mathrm{OL}$ & Involved in running the Leeds Jury & $1(\mathrm{OL})$ \\
\hline & & Total: 13 \\
\hline
\end{tabular}

\subsection{Case Studies}

The Oxford Citizens Assembly on Climate Change was run as part of the Council's response to their Climate Emergency Declaration in January 2019. The process was commissioned by Oxford City Council and was facilitated by Ipsos MORI, and an advisory group including key stakeholders was set up to provide governance and oversight of the process. The Assembly attempted to answer the question: 'The UK has legislation to reach 'net zero' by 2050 . Should Oxford be more proactive and seek to achieve 'net zero' sooner than 2050?.

Five themes which the council felt it had control and influence over - Waste Reduction, Buildings, Transport, Biodiversity and Offsetting and Renewable Energy - were selected to be covered in the process. Within each themes, Assembly members were then presented with three possible futures for Oxford related to how ambitious climate action would be in reaching 'net zero'. 42 residents were randomly selected as a representative sample of the city to participate, and the process ran over two weekends from September to October 2019. The recommendations produced from the process were very positive towards stronger climate action, with the majority of participants voting for the most ambitious scenario in each theme covered (Ipsos MORI, 2019).

The Assembly was well received by the Oxford City Council, who responded in December 2019 by setting a Climate Emergency Budget committing over $£ 1$ million additional funding and $£ 18$ million of capital investment to address the climate emergency. The council further committed itself to a range of actions, such as ensuring the organisation was net-zero by 2020, which has now been pushed back to the end of 2021, establishing a Zero Carbon Oxford 
Partnership, creating new carbon budgets and more (Oxford City Council, 2019; Oxford City Council, 2020). The Council also outlined its current and future plans to reach net zero in each area covered in the Assembly and claimed in its Cabinet report that the Assembly had informed the Council's plans to be more ambitious in achieving net zero (Tullar \& Colwell, 2019). The council further claimed that the Assembly would feed into its Sustainability Strategy in early 2020, although this is yet to be published (Oxford City Council, 2019; Oxford City Council, 2020). Nevertheless, the Council have published their 4th Carbon Management Plan for 2021/22-2029/30, which outlines how they will become a zero carbon council by 2030 (Oxford City Council, 2021). The Council also held a youth climate summit on the 28th of November 2020, which was part of their response to the Assembly (Oxford City Council, 2020). Thus, this suggests that the Assembly is influencing Oxford City Council's climate policies.

The Leeds Climate Change Citizens Jury was run in 2019 as part of the Big Leeds Climate Conversation which began after Leeds City Council declared a Climate Emergency and was run by the Leeds City Council and the Leeds Climate Commission. The Jury was commissioned and funded by the Leeds Climate Commission. The Jury was to guide the future work of the Commission, and Leeds City Council agreed to formally respond to the recommendations. The Jury was facilitated by professionals from Shared Future and an oversight group made up of key stakeholders oversaw the process. The key question presented to the Jury was: 'What should Leeds do about the emergency of climate change?. 21 residents were recruited as an inclusive sample of the city, and the Jury was run through eight evening sessions. The Jurors chose four topics which they wanted to focus on in more detail during the process: transport, communication and community involvement, housing, and finance. 12 recommendations were made on a broad range of issues and were ordered in terms of how many votes they received, and members also requested progress reports every 3 months for a year after the Jury ended (Shared Future, 2019).

The Big Leeds Climate Conversation, as a whole, influenced the January 2020 Council Climate Emergency Update Report (Cook \& Evans, 2020). The report contained a brief description of the Citizens' Jury and claimed that its recommendations would be presented to the Council's Climate Emergency Advisory Committee (CEAC). The report also referenced the recommendation on the use of green bonds and crowd-funding when discussing a project the Council was running to explore the use of crowd-funding to finance PV systems on Council buildings. The March 2020 CEAC response to the Jury welcomed its contribution, claimed support for the recommendations and outlined the council's plans in regard to the areas they covered (Cook \& Evans, 2020). Thus, this suggests that although the Council supported the recommendations, the process did not directly lead to new climate-related policies.

The two processes differed in many key ways. The Oxford Assembly process included 42 participants for a population of 152,450, whereas the Leeds Jury included 25 participants for a population of 793,139 (Oxford City Council, 2019; Leeds Observatory, 2019). The Oxford Assembly engaged a marginally bigger proportion of the population in the process, although in both processes the samples were small (less than $1 \%$ of the voting population). Both processes made efforts to have an inclusive range of participants and reflect a broad range of views. The Oxford Citizens' Assembly was run directly by the City Council whereas the Leeds Citizens' Jury was run by the Leeds Climate Commission, although it was endorsed by the City Council. The framing of the question was quite narrow in Oxford, focusing on the net-zero goal and whether the city should be more ambitious. In contrast, in Leeds the question was very broad, focusing on the city as a whole and its overall response to the climate emergency. The decision to pre-select the themes and options for the recommendations in Oxford and focus on those that the Council could control or influence meant that although the participants had little say in what was covered, the outcomes of the process were more focused on the key areas the council wanted to engage with citizens on. In contrast, in Leeds the participants choosing the themes to be covered meant that the process was more citizen-led.

\section{Findings}

\subsection{Purpose of the process}

The key reasons for using the Citizens' Jury and Assembly processes were broadly aligned in both Oxford and Leeds. The imperative to act after declaring a Climate Emergency, while bringing citizens on board, was a strong driver in both cases (LGL4, LGL3, LGO2, LGO3). Interviewees highlighted a desire to increase citizen engagement on climate change to encourage behavioural changes (LGL1, LGL2, LGL4, LGO3), involve citizens in climate policy-making rather than imposing policies on them (OL, LGL2, LGL4, 001) and better educate citizens on climate change (OL, LGL2, LGO1). In Leeds, interviewees saw the value of gathering deliberated opinions from citizens' from diverse backgrounds, giving them an opportunity to gain an in-depth understanding of how policies will affect different people (PL, LGL2, LGL3). Furthermore, in both cities the processes were seen as an opportunity to engage with the public and assess views on more ambitious climate change policies (LGL4, LGO3, LGL3, PO, LGL2).

"I think the principal thing for our citizens' assembly was, in Oxford was, how ambitious do these people want us to be, and how ambitious do they want the councillors to be." (LGO3)

Thus, our evidence suggests that these processes were used in order to increase informed citizen engagement in climate issues and policy-making, and to gather informed and diverse public opinions on climate action. The purposes of these processes was not to directly devolve decision-making power to participants, but rather to explore and integrate these deliberative democratic practices within existing institutional arrangements and representative democracy structures.

\subsection{Structure of process}

The most significant difference between the Oxford and Leeds processes in terms of structure was the choice of question and topics. In general, interviewees from Oxford were positive about the decision to limit the number of topics to be covered beforehand, indicating that the Assembly focused on areas that the council felt they could control or influence (LGO3, LGO2) and did not want to overwhelm participants with too much information (LGO2). Indeed, such a tight framing of the themes can allow the final recommendations to deliver clear messages to policymakers on what actions to take (Bryant \& Stone, 2020). However, an assembly with a pre-determined structure may be performing more of an consultative role rather than genuine citizen engagement as they are choosing from a list of pre-prepared strategy options, denying citizens the opportunity to present their own solutions to issues (Bryant \& Stone, 2020).

Page 5/12 
'Based on that evidence base of ok where is our biggest emitting sectors we do know that's where we need to focus and on top of that, yeah lots of discussion with various sort of experts in the field of what... was important to include'(LGO4)

Yet, there were some suggestions that despite limiting the Assembly to cover five themes, the scope had still been too broad given the amount of time it had and its task to assess both a net-zero target date and the participants views of the actions required in each level of ambition within the themes (002, 001 , LG01).

'I do think it was too many in that there wasn't sufficient time for people to be given to think through the complexities and what they thought about them in specific cases.'(002).

In Leeds, participants selected the topics discussed in the process, focusing on those they felt were important to tackling climate change in Leeds, making the process more citizen-led ( $\mathrm{PL})$. As the Jury was on the climate emergency in general and run by the Leeds Climate Commission, it was set up as a wide-ranging process (LGL4). Furthermore, the broad structure of the Jury allowed participants to come up with recommendations which were not necessarily on the Council's or Climate Commission's agenda, such as that which recommended stopping the Leeds Bradford airport expansion (PL). This open structure arguably allowed the jury to challenge existing policy which is important in the context of climate change where policy-decisions such as allowing the airport expansion could negate all other efforts to combat climate change in the city. This suggests that creating scope for participants come up with their own recommendations in these processes is important (PL). However, there were suggestions that the scope covered in the Jury had been too broad (LGL2, LGL4).

'That would be one of my reflections that it's just too broad a topic, you know they had something like 30 hours I think but even so, you know, 30 hours talking about the climate emergency and public transport and housing and financial markets, you know you can't go into depth on anything.'(LGL4)

Overall, this suggests that the structure of the citizen assembly or jury has a big impact on the type of citizen engagement achieved in these processes, as it determines whether the recommendations produced are citizen-led or reflect a more consultative process of citizen participation.

\subsection{Impact of the process}

In both cases the Councils responded to each recommendation with reference to their existing or planned actions in those areas and reference them in some reports as supporting initiatives which are in line with the recommendations (OL, LGL3), both of which according to Font and Smith (2013) suggests that they are having some influence. We can make a distinction between these processes having a direct impact (e.g. the recommendations get directly turned into policy) or an indirect impact (e.g. through influencing policy-makers and participant's views on climate change and climate action).

\section{Direct impacts}

The direct impact of the recommendations produced through the assembly and jury varied. In Leeds interviewees indicated that the recommendations were too broad or vague to provide useful insights for specific and complex policy-issues such as improving energy efficiency in housing (LGL2) or citizen engagement with and communication of climate change to the public (LGL4). This supports the argument by Font and Smith (2013) that vague recommendations may not offer useful guidance to policy-makers, suggesting that if a citizen jury or assembly is being used to inform policy-making on specific issues rather than gage broader public opinion it may be more useful to run them on narrower topics so they can be studied in depth and produce focused and practical outputs.

"In my view, the recommendations need to be SMART. Specific, measurable, achievable, realistic and time-bound. Well, specific, I don't think they're as specific as they could have been..." (LGL1).

Nevertheless, in Leeds the recommendations aligned with the Council's plans to tackle climate change and interviewees claimed it endorsed pre-existing policies or initiatives (LGL2-4). Yet, the jury was part of a wider process of citizen engagement, the Big Leeds Climate Conversation (LGL4) which makes its' impact on climate policy-making more difficult to identify, and was run by the Leeds Climate Commission rather than the council itself which may have influenced the extent to which the council felt it had to act in response to the Jury.

"The results from the citizens' jury aligned very very closely with what the, the council, you know, was intending to do anyway, so it was a kind of a, kind of an endorsement verification process." (LGL3)

In Oxford, interviewees highlighted that the Citizens Assembly provided support for the introduction of a policy package including $£ 19$ million additional funding on climate change, which one interviewee claimed had been drafted and approved beforehand but was presented as a response to the assembly (LG01, 001, PO). Yet, it was suggested that Oxford City Council's response to the recommendations had been delayed by the COVID-19 pandemic, implying that it could have more of an impact in the long-term (0O2). Nevertheless, one interviewee claimed that the Assembly supported pre-planned policies rather than changing the councils' approach, which suggests that the Assembly did not change the council's policies although this may be expected given the Assembly was framed according to the councils' climate policy options (LG01, LGO3).

'...it was all things they were going to do anyway. Nothing changed in the local plan for instance, so the local plan that we've just adopted will not see all new buildings being zero carbon. They could've put it in but they didn't.' (LG01)

'I don't think we would have done what we did in the time-scale that we did without that process... it's really helped put it on the agenda and as an organisation it's completely flipped what our corporate policies are... zero carbon became one of our primary corporate priorities and for the first time as well it meant the whole organisation had to be engaged'(LGO4) 
The lengthy process of writing, approving and implementing policy was also referenced, suggesting that the influence of the citizen jury and assembly recommendations may be seen in years to come, but also that pre-existing policies that are being put into place are not always a direct consequence of the processes (LGO1, LGL1). However, in both cities there was mention of how the recommendations were not intended to directly make policy decisions, and some interviewees expressed doubt that the recommendations would have a direct impact on policy (LGL3-4, 002, LGO1, LGL1). This implies that citizen juries and assemblies on climate change are playing an advisory role, providing legitimacy for and momentum to launch pre-planned policies at a faster pace rather than truly empowering citizens in decision-making (Wakeford et al., 2015). If these processes are to represent citizen engagement on climate change rather than citizen participation it should be clear from the beginning how the process will inform decision-making, as some interviewees implied that they were unsure what impact the processes had had or why it was used (LGL1, LG01, LGL4; Goodin, 2008).

The influence of the recommendations may reflect the stage in decision-making in which they were used, as Roberts and Escobar (2015) claimed that citizen assemblies are most influential if done at the agenda-setting stage of the policy process, rather than when policy approaches had been drafted as was the case in Oxford where participants chose between a narrower set of options to form their recommendations. Yet, climate policy-making is ongoing and the processes still may play an agenda-setting role by indicating the level of ambition the council should strive for (Roberts \& Escobar, 2015).

\section{Indirect impacts}

The value of the processes in creating momentum and giving politicians and policy-makers greater confidence to pursue stronger measures on climate change was highlighted in Leeds and Oxford. In Leeds the Jury created momentum and gave officials backing for stronger measures by increasing their confidence that the public would be supportive of them (LGL2, OL). Similarly, in Oxford interviewees highlighted how the Assembly created momentum by pushing the Council to be more ambitious in their climate action and reassuring politicians of the public's support (LGO2-4, 002-1, LG01). This supports the argument that the biggest impact these processes have is to create a strong political platform for action by providing elected representatives with a public mandate on climate change (Bryant \& Stone, 2020). Yet, the need for the momentum to be sustained in the long-term by continued reference to the recommendations by other actors in the city was highlighted in Leeds $(\mathrm{OL})$.

"It gave the political leadership...the political momentum to push through more funding... for low carbon initiatives." (001).

"it certainly added weight and credibility and helped with momentum, would it, would it completely change the councils views on something, probably not" (LGL2).

Furthermore, the citizen assembly and jury processes were valued as tools to help overcome some of the key challenges climate action faces. In Oxford, the Citizens' Assembly was seen as a response to and an opportunity to overcome the struggle within the political system to effectively tackle climate change (PO). Reasons for this included short political cycles clashing with the long-term issue of climate change (LGO3), the lack of trust in governments and influence of lobbyists such as the fossil fuel industry (001), and the failure of elections in informing government of public opinions on climate change as votes generally reflect people's short-term interests (LGO1). This was also suggested in Leeds, where the citizens' jury was described as an alternative and deliberative form of democracy outside of the normal realm and challenges of local government (LGL3-4).

"If you just leave it to the ballot box, it's hopeless. I mean our democracy is fundamentally broken, you know, it doesn't tell you what people think about climate change because they're more interested in what bus routes are running and things like that, you know, it's short-term stuff." (LGO1)

"Politicians are absolutely driven by the political cycle... and a lot driven by what is in the public domain and in the press, so they... really do react to that kind of reputational arena, and you and I both know that sustainability is a long-term issue... and those aren't great in a 4 or 5 year political time-scale, and we've got a kind of clash between a long-term and quite potentially 'unsexy' area of work, against political priorities, press, the need for new and news...." (LGO3)

Furthermore, in both cities the processes demonstrated that citizens who are educated on climate change and the various issues surrounding it through the right communications are more likely to be supportive of and engaged in stronger climate action (LGL2, OL, LGO2). Additionally, interviewees highlighted that better educating and communicating with citizens on climate change was recommended in both processes. Thus, the processes seem to have encouraged the councils' and other parties to increase and improve future citizen engagement on climate change more broadly (LGO2-4). However, in Leeds it was suggested that the Jury could have provided more in-depth insights into how the participants thought communications could be improved to engage the public in climate change debates, highlighting the desire for more practical recommendations (LGL4).

'Part of what came out of it was a huge engagement programme and actually some of that has survived... we were due to do workshops and all sorts... that was not something we were planning to do before this process so, yeah huge engagement programme now lined up.'(LGO4)

Therefore, the indirect impact of deliberative democratic processes can be significant and positive. Participants themselves find the experience enriching, and politicians and policy-makers can find it emboldening and reassuring in their chosen policy path, balancing some of the other influences they are usually subject to (e.g. the media, lobbying groups, electoral cycles).

It is important to critically analyse how these processes are being run and the impact they have in practice. Direct impacts or indirect impacts may not be immediately apparent, which led to some interviewees raising concerns that the impacts of these processes were not being critically assessed due to the heightened attention on climate change action (LGL4, LGL1)

'I looked at the recommendations, I think it was Camden because there weren't that many before ours, and I read the recommendations and I thought exactly the same as I thought about ours, that it didn't tell me anything I didn't already know. But if you were to listen to the politicians at Camden speaking, well it's the best thing that's ever happened, you know it's really changed the world, you know I struggle to see that, but I think it's a bit like the emperor's new clave, if 
you know what I mean by that, that you're almost on the wrong side of life if you're not saying they're great, because everybody's just singing and dancing,' (LGL4).

The role that citizen assemblies and juries on climate change were seen to have within the wider democratic policymaking process was unclear. There was a feeling that if these types of process were to have a direct impact on policies it would be undemocratic (LGL2). Again this represents a tension of how to embed deliberative democratic practices that involve the public directly within institutional arrangements based on representative democracy, a tension between giving some power back directly to a group of citizens, potentially at the expense of elected councillors.

"There was an implication by a few people... it was almost like we should leave it to the jury and just do what the jury says... well that's not a position that a democratic body would take, it wouldn't actually say you know, we have been elected by the electorate but we are actually going to in some senses abdicate responsibility and allow a jury to determine policy, it's got to be, it's a form of, informed consultation, and kind of consultation has a weight obviously." (LGL2)

\subsection{Engagement with the wider public}

There was agreement in both cities that the citizens' jury and assembly needed to better draw the wider public into debates on climate change. The value of the Leeds Jury in relation to its cost was questioned due to its perceived failure to influence or draw a significant proportion of the wider population into climate change debates (LGL1, LGL4, LGL3). This implies that in order for these processes to be seen as worthwhile they need to engage the wider public in climate debates. Similarly, the failure to energise and involve the wider public through the process of organising the Oxford Assembly was criticised (001, LG01). This suggests that citizen juries and assemblies on climate change present an opportunity to engage with the wider public and build trust, an opportunity which was missed in these two instances. Better media coverage of citizens' juries and assemblies on climate may engage and communicate with the public more deeply on the debates had in and generated by these processes (Goodin, 2008; Delap, 2001; Devaney et al., 2020, Capstick et al., 2020). Thus, broader citizen engagement should be a key focus for future climate citizen juries and assemblies for them achieve their engagement potential and be worthwhile processes.

'Ultimately you know 25 people across 800,000, you know they might each go back and talk to 10 people but that still only reaches 250 . So I think there's something about trying to work out how you get more out of that legacy, and how they become more kind of influential (...) it can be quite a limited role if that kind of legacy bit is not properly planned out and talked through.'(LGL4)

'The very process of organising a citizens' assembly should energise and involve in it, you know lots of people, and that wasn't really achieved.'(001)

Interviewees suggested that citizen assemblies and juries could be used again in the future with a narrower scope or at more local scales (001, 002, LGL4). Before the COVID-19 pandemic there was discussion in Leeds of having citizens' juries at a regional-level on adaptation (LGL3) and in the city on transport as this was highlighted as being a particularly contentious and difficult issue (LGL2, LGL3, LGL4). Thus, this suggests that policy-makers saw these as being useful processes for engaging with citizens on contentious climate-related issues.

"I don't think just having more and more citizens assemblies in the same place on, on climate change is, is the way forward (...) actually, you probably need to go to the next level of granularity and ask questions like, well, what, what should Oxford's transport system look like?" (002)

\subsection{Value for money}

Citizen juries and assemblies were frequently referred to as expensive processes, especially in Leeds where funding primarily came from research grants (LGL3-4, OL, LG01, LG03-4). The price of the Oxford Assembly process was estimated at $£ 200,000-£ 250,000$ (LG01, 001) and the Leeds Jury at $£ 30,000-$ $£ 40,000$ ( $L G L 3, L G 4, O L$ ). Consequently, there was concern over how to make them more accessible as most local authorities or organisations lack funding to run these processes, especially given the wider context of the pandemic, or prioritise delivering projects rather than extensive public consultations (OL, LGL3). The use of other deliberative tools on narrower topics was suggested as alternative way to engage with citizens on climate change (PL, 002). Focus groups were identified as being as good or better tools to gage public opinions on specific issues due to the in-depth discussions and practical insights they can provide and the lower cost of running them (LGL3, LGL4, LGO4). Moreover, other methods of informing the public was suggested as being better value for money, such as a radio campaign or educational programme in schools which may reach more people, further emphasising the need to involve the wider public in these processes if they are to be worthwhile (LGL4).

'I think yeah reflecting on the amount of staff that was involved and the money it cost to run it, you have to reflect on whether there are more effective ways, or at the end of the day this is what it comes down to whether there are cheaper ways to achieve something similar.'(LGO4)

'Has it raised greater awareness, maybe but there's no kind of evidence to show that, in which case you know I think our kind of assessment up front was that it was a lot of money to talk to 25 people even though they come away as really good advocates, unless they're advocates that go out and talk to 1,000 people or you know, from a value for money perspective you know it's not the best value for money.' (LGL4)

Yet, the value of having an inclusive sample participating in a jury or assembly was highlighted, suggesting that in-depth citizen engagement with a representative sample at more affordable rates was desired (LGL4). However, this is difficult to achieve as recruiting representative samples is a resourceintensive process (OL, LGO4). Therefore, the price of running and the small number of the target population which they engage seems to be key challenges to these processes.

'You know those 24 people in Leeds they came up with recommendations which were broadly consistent with what we were going to be doing anyway, so that, that, that's interesting, that's an interesting thing, but given that that's the fact then could we use that 30,000 pounds maybe to try and get carbon literacy in I don't know, the 5 largest employers in the city and maybe reach, I don't know, 20,000 people'(LGL3). 


\section{Discussion}

The two case studies have allowed us to draw some important links between the topics discussed in Sect. 2, tied by common threads: meaningfulness of participation, legitimacy and effectiveness. In this section we will analyse each of these in turn.

The meaningfulness of participation relates to how the inputs from participants were conceived, both before and after the processes. The interviewees primarily saw these processes as a way to increase engagement, educate participants and learn about different impacts of policies they were considering or may have overlooked. Therefore, it is not surprising that many interviewees did not report any direct impacts from the processes, at least not for now. Some interviewees also failed to identify any indirect impacts and implied that the link to decision-making was unclear. Some even suggested that these processes could have been replaced by focus groups or increased climate/carbon literacy suggesting a doubt in the value of the process. If participation is not considered in a meaningful way from the beginning, it is difficult for it to become meaningful down the line. Therefore, both the direct and indirect impacts should be clear to participants and commissioning bodies from the beginning of these processes.

The thread of legitimacy linked aspects of the purpose, structure and impacts of the processes. In terms of structure, the Oxford Citizen Assembly on Climate Change and the Leeds Climate Change Citizen Jury differed in the extent to which they truly engaged with the public. In Oxford, the decision to pre-set the topics discussed and the shape of the recommendations created more of a consultative process of citizen participation than citizen engagement as the process was not necessarily citizen-led. In contrast, in Leeds the jurors decided on the topics to be discussed and wrote the recommendations themselves, suggesting that this structure better represents genuine citizen engagement.

Questions of who held power to design policies, a small group of citizens or elected representatives, were highlighted. On the one hand, it was interesting to see how there was some reluctance to allow the mini-publics to directly design (in the case of Oxford with pre-determined policy options) or influence the design of specific policies (in the case of Leeds where so far the recommendations have not resulted in specific policies). On the other, referring to responsibility and accountability, the jurors or assembly members had no official or institutional responsibility, and thus no accountability, to the rest of the citizenry, and thus their decision could be considered illegitimate (Fuller, 2019).

Finally, the thread of effectiveness also surfaced in the impact and engagement with the public themes. Two elements are key: the indirect impacts and the stage in the decision-making process at which these processes were undertaken. In relation to the latter, mini-publics at the agenda setting stage might avoid some issues of legitimacy (because they do not lead to specific policies), as well as being more effective in steering policy-making in a certain direction and providing more meaningful participation to those involved. Then the issue of the trade-off between breadth and depth, and thus vague or specific recommendations, becomes clearer, because mini-publics would deliberate on broader directions and priorities, while specific policies could be developed at a later stage by elected representatives while including citizens more broadly. In relation to the former, we consider the indirect impacts to be particularly important. The effect on policy-makers can be vital, providing a way of re-balancing the sources of influence they are subjected to, giving a group of inclusive citizens a louder voice. In both cities the value of the processes in creating more momentum to act on climate change was highlighted, enabling an increase in the pace of climate action, especially in Oxford.

However, the failure to engage with the wider public on climate change through the processes was highlighted as a missed opportunity, while the value for money of the processes considering the small number of participants which were engaged was questioned. Thus, although citizen juries and assemblies have the potential to engage with the wider public, they have not always done so. In order for these processes to be seen as worthwhile given their high cost they should aim to engage the wider public in debates had during the processes through large-scale communication campaigns for example, although this would likely increase their cost further.

The impact of the COVID-19 pandemic on the outcomes of these processes and climate action have been significant. Interviewees claimed that the increased funding which had been allocated to climate change in Oxford City Council's budget has disappeared due to the large financial impact of the pandemic, suggesting that the pandemic is slowing down and perhaps even preventing city-level climate action. In Leeds a citizens' jury specifically on transport was being considered, yet due to the financial impact of the pandemic it is unlikely the council will be able to fund it. Similarly in Oxford the pandemic has disrupted plans to engage further with the public. However, in both cities it seemed that the momentum behind climate action had not disappeared and that climate change was still a priority. Nevertheless, the economic impact of the COVID-19 pandemic on councils may affect their ability to run citizen juries and assemblies on climate change in the future, and may stall climate action.

\section{Conclusion}

This study suggests that the direct impact of citizen juries and assemblies on climate change policymaking is not uniform, and depends on the stage at which they are conducted, who commissions them, their structure and how meaningful citizen participation is designed to be. However, their indirect impact can be significant, especially by balancing the sources of influence that policymakers are subject to and increasing political momentum for further and faster climate action by councils.

Furthermore, it seems that there is a missed opportunity in these processes to engage the wider public in debates around climate change and how it should be tackled. Thus, this suggests that future citizen juries and assemblies should seek to utilise the momentum generated by these processes as a tool not only to engage the participants in climate change debates but also to engage the wider public in the process and its content to improve legitimacy and promote learning and engagement. Nevertheless, both processes recommended more communications with the public on climate change which both councils seem to have taken on board, implying that citizen assemblies and juries on climate change may encourage councils to increase their work to engage citizens in the debates around climate change. 


\section{Declarations}

\section{Ethical Approval}

Ethical approval was obtained from the LSE Ethics Committee March 2020.

\section{Consent to Participate}

Written, signed consent was obtained by all research participants.

\section{Consent to Publish}

Consent to publish obtained by research participants.

\section{Authors Contributions}

RW conducted the interviews and led the interview analysis, $\mathrm{CH}$ contributed to the theoretical discussion and oversaw the interview analysis, LIB-C contributed to the theoretical discussion. All contributed to drafting the paper.

\section{Funding}

The authors gratefully acknowledge support from the UK Economic and Social Research Council through the Place-Based Climate Action Network (P-CAN) (Ref. ES/S008381/1).

\section{Competing Interests}

The authors declare no competing interests.

\section{Availability of data and materials}

Data is freely available.

\section{References}

Baxter J \& Eyles J (1997) Evaluating qualitative research in social geography: establishing 'rigour' in interview analysis. Transactions of the Institute of British Geographers, 22(4), 505-25.

Braun V \& Clarke V (2018) Interactive data collection: Interviews. In: Braun \& Clarke eds. Successful qualitative research: a practical guide for beginners. London: SAGE, 77-106.

Bryant P (2019) Citizens' Assemblies, Citizens' Juries and Climate Change. Available at: https://sharedfuturecic.org.uk/citizens-assemblies-citizens-juries-andclimate-change/.[Accessed 1/08/2020].

Bryant P \& Hall J (2017) Citizens Jury Literature Review. Shared Future.

Bryant P \& Stone L (2020 Climate Assemblies and Juries: A people powered response to the climate emergency: A guide for local authorities and other bodies. Shared Future.

Capstick S et al (2020) Climate Change Citizens' Assemblies. CAST Briefing Paper 03. Available at: https://cast.ac.uk/wp-content/uploads/2020/03/CASTBriefing-03-Climate-Change-Citizens-Assemblies.pdf [Accessed 4/05/2020].

Carpini MXD, Cook FL \& Jacobs LR (2004) Public Deliberation, Discursive Participation, and Citizen Engagement. Annual Review of Political Science, 7, $314-44$. Chrisafis A (2018) Who are the gilets jaunes and what do they want?. Available at: https://www.theguardian.com/world/2018/dec/03/who-are-the-giletsjaunes-and-what-do-they-want

Climate Change Committee (2019) Net Zero: The UK's contribution to stopping global warming. Committee on Climate Change.

Cook P \& Evans N (2020) Climate Emergency Update, Leeds: Leeds City Council.

Cook P \& Evans N (2020) Item 10-Response to the Citizens' Jury's Recommendations. Report to Climate Emergency Advisory Committee. Leeds: Leeds City Council.

Corner A, Demski A, Steentjes K \& Pidgeon N (2020). Engaging the public on climate risks and adaptation: A briefing for UK communicators, Oxford: Climate Outreach.

Declare A Climate Emergency (2020) List of Councils who have declared a climate emergency. Available at: https://www.climateemergency.uk/blog/list-ofcouncils/ [Accessed 5/08/2020]

Delap C (2001) Citizens' juries: reflections on the UK Experience. PLA Notes 40. Available at: http://pubs.iied.org/pdfs/G01929.pdf [Accessed 10/07/2020]. 
Devaney L, Torney D, Brereton P \& Coleman M (2020) Ireland's Citizens' Assembly on Climate Change: Lessons for Deliberative Public Engagement and Communication. Environmental Communication, 14(2), 141-6.

Dietz T \& Stern PC (2008) Public Participation in Environmental Assessment and Decision Making. Available at: https://doi.org/10.3389/fenvs.2019.00010. [Accessed 1/05/2020].

Elstub S (2011) A comparative analysis of the role of minipublics in institutionalising deliberative democracy. London, Political Studies Association Annual Conference.

Extinction Rebellion Citizens' Assemblies Working Group (2019) The Extinction Rebellion Guide to Citizens' Assemblies. Available at: https://rebellion.earth/wp/wp-content/uploads/2019/06/The-Extinction-Rebellion-Guide-to-Citizens-Assemblies-Version-1.1-25-June-2019.pdf [Accessed $7 / 07 / 2020]$.

Flinders M et al (2015) Democracy Matters: Lessons from the 2015 Citizens' Assemblies on English Devolution, s.l.: Democracy Matters.

Font J \& Smith G (2013) The policy effects of participation: Cherry-picking among local policy proposals?, Bordeaux: Presented at ECPR General Conference.

Fuji LA (2018) Interviewing in Social Science Research. New York: Routledge.

Fuller R (2019) In Defence of Democracy. Cambridge, UK and Medford, MA: Polity Press.

Goodin RE (2008) Innovating Democracy: Democratic Theory and Practice After the Deliberative Turn. Oxford: Oxford University Press.

Goodin RE \& Dryzek JS (2006) Deliberative impacts: The macro-political uptake of mini-publics. Politics \& Society, 34(2), pp. 219-44.

Howarth C et al (2020) Building a social mandate for climate action: Lessons from COVID-19. Environmental and Resource Economics: Special Issue 'Environmental Economics in the Shadow of Coronavirus', 76, 1107-1115.

Howarth C, Barry J, et al (2021) Trends in Local Climate Action in the UK. A report by the Place-Based Climate Action Network (PCAN). UK

Involve (2020) Citizens' Assembly Tracker. Available at: https://www.involve.org.uk/citizens-assembly-tracker. [Accessed 13/01/2021].

Ipsos MORI (2019) Oxford Citizens' Assembly on Climate Change: A summary report prepared for Oxford City Council, Oxford: s.n.

Jacquet V (2019). The Role and the Future of Deliberative Mini-publics: A Citizen Perspective. Political Studies, 67(3), $639-657$.

Kythreotis AP \& et al (2019) Citizen Social Science for More Integrative and Effective Climate Action: A Science-Policy Perspective. Frontier Environmental Science.

Lafont C (2017) Can democracy be deliberative \& participatory? The democratic case for political uses of mini-publics. Daedalus, 146(3): 85-105.

Lamb WF, Antal M, Bohnenberger K, et al (2020) What are the social outcomes of climate policies? A systematic map and review of the ex-post literature. Environmental Research Letters, 15: 0-31. https://doi.org/10.1088/1748-9326/abc11f.

Leeds Observatory (2019) Population of Leeds. Available at: https://observatory.leeds.gov.uk/population/ [Accessed 20/11/2020].

Mellier C \& Wilson R (2020) Getting Climate Citizens' Assemblies Right. Available at: https://carnegieeurope.eu/2020/11/05/getting-climate-citizensassemblies-right-pub-83133. [Accessed 1/12/2020].

Niemeyer S (2013) Democracy and Climate Change: What Can Deliberative Democracy Contribute?. Australian Journal of Politics and History, 59(3), pp. 42948.

Oxford City Council (2020) City Council to hold Oxford's first Youth Climate Summit. Available at: https://www.oxford.gov.uk/news/article/1491/city_council_to_hold_oxford_s_first_youth_climate_summit

[Accessed 20/11/2020].

Oxford City Council (2019) City Council responds to Oxford Citizens' Assembly on Climate Change and outlines 19million pound climate emergency budget. Available at:

https://www.oxford.gov.uk/news/article/1275/city_council_responds_to_oxford_citizens_assembly_on_climate_change_and_outlines_19m_climate_emergenc) [Accessed 20/10/2020].

Oxford City Council (2019) Oxford's Population. Available at: https://www.oxford.gov.uk/info/20131/population/459/oxfords_population

[Accessed 20/11/2020].

Oxford City Council (2020) Zero Emission Zone Pilot proposal out for final consultation. Available at:

https://www.oxford.gov.uk/news/article/1625/zero_emission_zone_pilot_proposal_out_for_final_consultation [Accessed 20/11/2020]. 
Oxford City Council (2020) Oxford City Council announces city has achieved 2020 emissions reduction target and sets date for Zero Carbon Oxford summit. Available at:

https://www.oxford.gov.uk/news/article/1654/oxford_city_council_announces_city_has_achieved_2020_emissions_reduction_target_and_sets_date_for_zero_c [Accessed 13/02/2021].

Oxford City Council (2020) Oxford City Council holds Youth Climate Summit on how city can tackle the climate emergency. Available at:

https://www.oxford.gov.uk/news/article/1629/oxford_city_council_holds_youth_climate_summit_on_how_city_can_tackle_the_climate_emergency. [Accessed $13 / 02 / 2021]$.

Oxford City Council, 2021. Council outlines how it aims to become a Zero Carbon Council by 2030 at the latest. Available at: https://www.oxford.gov.uk/news/article/1705/council_outlines_how_it_aims_to_become_a_zero_carbon_council_by_2030_at_the_latest. [Accessed $13 / 02 / 2021]$.

Rapley T (2011) Encountering method: Interviews. In: Qualitative Research Practice. London: SAGE Publications Ltd., 16-34.

Roberts J \& Escobar O (2015) Involving communities in deliberation: A study of three citizens' juries on onshore wind farms in Scotland, Edinburgh: ClimateXChange.

Rode P (2019) Climate Emergency and Cities: An urban-led mobilisation?. LSE Cities Discussion Papers, Research Strand 02: Cities, Climate Change and the Environment.

Seale C, Gobo G, et al (2011) Introduction: Inside Qualitative Research. In: C. Seale, G. Gobo, J. F. Gubrium \& D. Silverman, eds. Qualitative Research Practice. London: SAGE Publications Ltd, 1-13.

Shared Future (2019) Leeds Climate Change Citizens' Jury recommendations. Available at:

https://www.leedsclimate.org.uk/sites/default/files/CJ\%20recommendations\%20FINAL\%20_0.pdf [Accessed 10/06/2020].

Smith G \& Wales C (2000) Citizens Juries' and Deliberative Democracy. Political Studies, Volume 48, 51-65.

Steentjes DK et al (2020) British Public Perceptions of Climate Risk. Adaptation Options and Resilience: Topline findings of a GB survey conducted in October 2019, s.I.: UK Climate Resilience Programme.

Svara JH \& Denhardt J (2010) Connected communities: local governments as a partner in citizen engagement and community building, White Paper for Alliance for Innovation. Arizona State University.

Tullar M \& Colwell J (2019) Initial response to Report on Citizens' Assembly on Climate Change, Oxford: Oxford City Council.

Wakeford T, Walcon E \& Pimbert M (2015) Refashioning citizens' juries: Participatory democracy in action. In: H. Bradbury-Huang, ed. The Sage handbook of action research. New York: SAGE, 230-247.

Willis R (2018) Building the political mandate for climate action, London: Green Alliance.

Willis R (2019) Citizens' Assemblies and Citizens' Juries: What happens next?. Available at: https://www.rebeccawillis.co.uk/citizens-assemblies-and-citizensjuries-what-happens-next/ [Accessed 15/06/2020].

Willis R (2020) Too Hot to Handle? The Democratic Challenge of Climate Change. Bristol: Bristol University Press. 